\title{
Comparison of Short-Segment Pedicle Instrumentation with Supplemental Hook Fixation under Axial Compression in Relation to Graft Positioning and Posterior Ligamentous Integrity: A Biomechanical Study on the Calf Spine
}

\author{
Sedit Kivanc Muratli ${ }^{1}$, Haluk Berk ${ }^{2}$ \\ ${ }^{1}$ Department of Orthopaedics and Traumatology, Canakkale Onsekiz Mart University, Canakkale, Turkey \\ ${ }^{2}$ Department of Orthopedics and Traumatology, Dokuz Eylul University School of Medicine, Izmir, Turkey
}

\begin{abstract}
Study Design: Biomechanical study.
Purpose: This study investigates the benefits of supplemental hook fixation (SHF) on short-segment pedicle instrumentation (SSPI) in relation to anterior strut graft positioning. In addition, it seeks to determine whether the integrity of the posterior ligamentous complex (PLC) affects the stability of the spinal construct.

Overview of Literature: Implant and/or bone failure with progressive kyphotic deformity after SSPI is common. To prevent this, several approaches are available, including SHF, anterior strut grafting, use of longer spinal constructs, and extension of the fusion to additional adjacent segments.

Methods: A total of eight calf spines were instrumented with SSPI $(n=4)$ and SHF $(n=4)$ with strain gauges on the implants. Strain measurements were performed under axial compression in the following order: intact spine, corpectomy, ventral positioned strut grafting, posterior positioned strut grafting, ventral positioned grafting with resected PLC, and corpectomy with resected PLC.

Results: The SHF group showed slightly lower strain values than SSPI in instrumented corpectomy-only specimens, but there were no statistically significant differences between them ( $p>0.05)$. The SHF group was significantly more stable than SSPI when strut grafting is employed, regardless of the location of the grafts $(p=0.000)$. In the SSPI group, ventral positioning of the graft contributed significantly to the stability $(p=0.000)$. There was no statistically significant difference between the ventral or posterior positioning of the graft in the SHF group ( $p=0.187)$. In addition, the integrity of the PLC did not affect stability in either group $(p>0.005)$.

Conclusions: Although not statistically significant, our investigation demonstrated that the most stable method was the SHF along with ventral positioned strut graft. However, if the SSPI is the treatment of choice, ventral positioned strut graft support will be useful in minimizing the risk of implant failure and progressive kyphotic deformity.
\end{abstract}

Keywords: Lumbar vertebrae; Spinal fractures; Biomechanics; Bone grafting; Instrumentation

Received Jul 5, 2019; Revised Aug 4, 2019; Accepted Sep 19, 2019

Corresponding author: Sedit Kivanc Muratli

Department of Orthopaedics and Traumatology, Canakkale Onsekiz Mart University, Ortopedi ve Travmatoloji A.D. Barbaros Mahallesi, Terzioglu Yerleskesi, Canakkale, Turkey

Tel: +90-5055250106, Fax: +90-2862183738, E-mail: skmuratli@hotmail.com 


\section{Introduction}

Short-segment pedicle instrumentation (SSPI) has been widely used for the treatment of instability after thoracolumbar burst fractures and spinal tumor resections [1-3]. It usually provides excellent initial correction of kyphotic deformity, but a significant loss of correction with progressive kyphotic deformity, implant, and/or bony failure may occur afterward [1,4-8]. Several methods have been recommended to prevent failure, including supplemental hook fixation (SHF), anterior strut grafting and/or instrumentation, use of longer spinal constructs, and extension of the fusion to additional adjacent segments [1,9-16]. De Peretti et al. [12] proposed the addition of laminar hooks (2HS-1SH method) and concluded that screw and hook fixation is effective for stabilizing burst fractures of the thoracolumbar junction. A combination of SHF with SSPI preserves the bone tissue and implant by decreasing the amount of load transfer in the bone-screw interface $[4,10,14]$.

The use of an anterior strut graft significantly increases the overall stiffness of the spinal construct while graft positioning anterior to the neutral axis of the spine provides a more optimal load sharing when posterior stability is obtained $[9,17]$. The posterior ligamentous complex (PLC) helps maintain stability by resisting excessive motion [1821]. The individual contributions of PLC ligaments to stability have been previously investigated [22-24]; however, to the best of our knowledge, there is no information regarding their role in posterior spinal instrumentation and/ or anterior strut graft procedures. Therefore, the current study has three main goals: first, to confirm the benefits (if any) of SHF to SSPI; second, to determine the effects of anterior strut grafting on SSPI and SHF regarding graft positioning; lastly, to determine whether the integrity of PLC impacts the stability of the spinal construct in terms of the type of instrumentation with and without the strut grafting. With the interpretation of these results, the study would be insightful for choosing the most stable method.

\section{Materials and Methods}

Eight calf spine specimens (6-9 months old) were used as the spine models. The specimens were kept at $-80^{\circ} \mathrm{C}$ until each test was performed. Five and seven vertebral segments proximal to the sacrum were used for the SSPI/ short segment (group 1) and SHF/long segment (group 2 ) groups, respectively. The proximal and distal vertebral segments were fixed in cylindrical molds using general purpose polyester. Sequential water cooling was done to avoid overheating of the specimens throughout the curing period of the polyester molds.

A stainless steel version of a standard type posterior spinal instrumentation system (YSS 316-L/4441Q; Hipokrat Co., Izmir, Turkey) with two crosslinks was used for the instrumentation. Six general purpose strain gauges (Type: FLA-1-11-1L; TML Tokyo Sokki Kenkyujo Co. Ltd., Tokyo, Japan) were used for each specimen. Four strain gauges were placed at the neck of the pedicle screws and two at the midline of each rod (Fig. 1). Room temperature and humidity were maintained at $22^{\circ} \mathrm{C}-24^{\circ} \mathrm{C}$ and $40 \%$ $60 \% \mathrm{rH}$, respectively, during the experiments. A 10-channel strain indicator (P-350; Vishay Instruments Co., Malvern, PA, USA) and a universal testing device (Autograph AG-50kNG; Shimadzu Co., Kyoto, Japan) were used for the tests (Fig. 1). The axial loading ratio was maintained

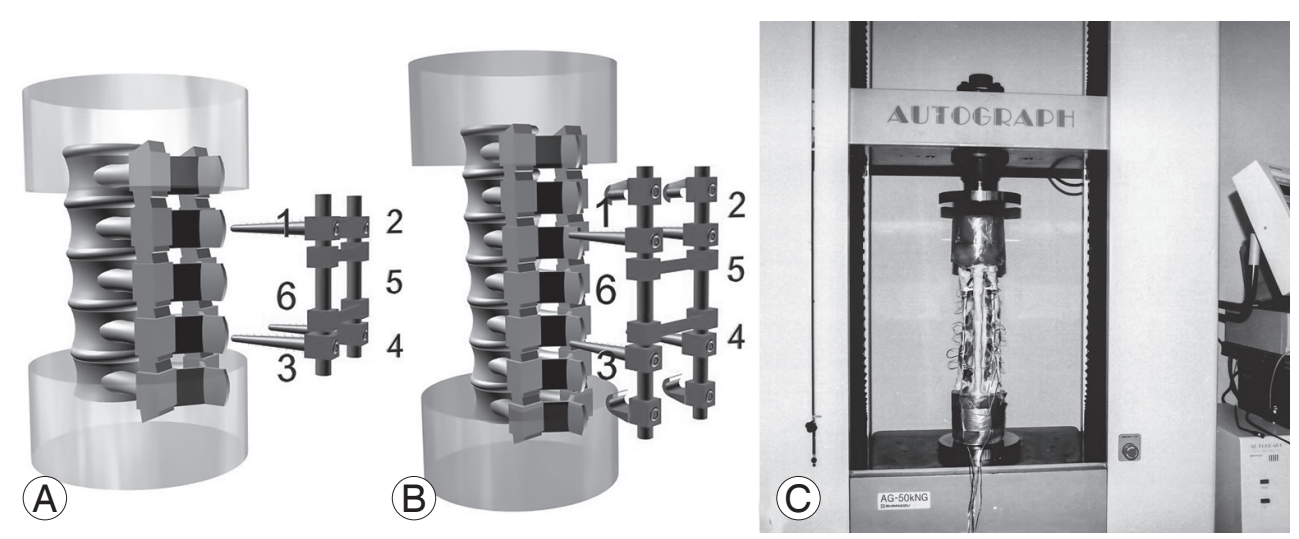

Fig. 1. (A, B) Illustration showing preparation of specimens and strain gauge locations. (C) Test specimen placed on the universal testing device. Exposed areas of specimens were covered with saline soaked gauze during the tests. 
between $0.5-0.05 \mathrm{~mm} / \mathrm{min}$ to avoid elastic relaxation of the system. Strain measurements were performed for each specimen in the following order: (1) calibration value, (2) $400 \mathrm{~N}$, (3) $500 \mathrm{~N}$, and (4) $600 \mathrm{~N}$ of axial loading. These values were selected to simulate loading conditions of the upper body weight in the standing position. Six tests were performed for each specimen: (1) intact spine (instrumented), (2) corpectomy (instrumented), (3) corpectomy (instrumented) and ventral/anterior positioned strut graft, (4) corpectomy (instrumented) and posterior positioned strut graft, (5) corpectomy (instrumented), anterior positioned strut graft, and resected PLC, and (6) corpectomy (instrumented) and resected PLC. Ventral/anterior graft positioning was performed by placing the strut graft in the anterior column and posterior positioning was performed by placing the strut graft in the middle column (of Dennis). PLC resections were performed by resecting the supraspinous ligament, interspinous ligament, facet capsule ligament, and ligamentum flavum.
Statistical analyses were performed using the Shapiro-Wilk test for normality of data distribution (selected for small "n" number) and Mann-Whitney U-test for nonparametric comparison of groups (SPSS ver. 16.0; SPSS Inc., Chicago, IL, USA). A $p$-value of $<0.05$ was considered to be statistically significant.

\section{Results}

\section{General comparison of short-segment pedicle instru- mentation and supplemental hook fixation groups}

Table 1 summarizes the data of the SSPI (group 1) and SHF (group 2) groups. A general comparison of these two groups demonstrated significantly lower strain values for the SHF group in test 3 (corpectomy and ventral strut graft), test 4 (corpectomy and posterior strut graft), and test 5 (corpectomy, anterior strut graft, and resected PLC) ( $p=0.000)$ (Table 1, Fig. 2). Tests 1 (intact spine), 2 (cor-

Table1. Summary of strain value measurements of both groups from all tests

\begin{tabular}{|c|c|c|c|c|c|c|c|}
\hline \multirow{2}{*}{ Variable } & \multicolumn{3}{|c|}{$\begin{array}{c}\text { Group 1: short-segment pedicle } \\
\text { instrumentation }\end{array}$} & \multicolumn{3}{|c|}{ Group 2: supplemental hook fixation } & \multirow{2}{*}{$p$-value } \\
\hline & Mean \pm SD & Median & Min-max & Mean \pm SD & Median & Min-max & \\
\hline Test 1: intact spine & $4.5936 \pm 3.841$ & 2.8877 & $0.61-11.15$ & $2.1736 \pm 1.9956$ & 1.7564 & $0.33-6.10$ & 0.290 \\
\hline Test 2: corpectomy & $28.7952 \pm 26.5260$ & 24.9565 & $2.08-79.47$ & $14.3961 \pm 14.8269$ & 6.2752 & $1.87-43.36$ & 0.166 \\
\hline Test 3: corpectomy and ventral strut graft & $10.3969 \pm 7.6930$ & 10.3706 & $0.76-24.32$ & $2.2426 \pm 2.3497$ & 0.8810 & $0.28-6.83$ & $0.000^{\mathrm{b})}$ \\
\hline Test 4: corpectomy and posterior strut graft & $38.0413 \pm 10.7966$ & 33.3064 & $26.25-58.77$ & $3.1711 \pm 3.4832$ & 1.0694 & $0.59-10.42$ & $0.000^{b)}$ \\
\hline Test 5: corpectomy, ventral strut graft and resected PLC & $8.1318 \pm 6.6774$ & 6.3405 & $0.88-18.40$ & $1.8349 \pm 1.9680$ & 0.7972 & $0.22-6.84$ & $0.000^{b l}$ \\
\hline Test 6: corpectomy and resected PLC & $21.5832 \pm 13.8106$ & 21.2631 & $2.29-44.99$ & $12.5759 \pm 14.2062$ & 3.4935 & $1.71-40.02$ & 0.065 \\
\hline
\end{tabular}

In tests 1, 2, and 6, group 2 shows lower strain ratios, but these were not statistically significant ( $p>0.05)$. Data expressed are strain measurements; strain is a unitless quantity: strain=dL (change in dimension)/L (original dimension).

SD, standard deviation; PLC, posterior ligamentous complex.

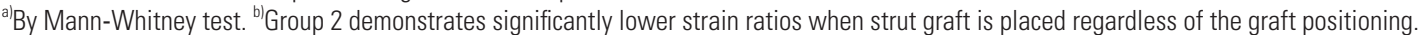
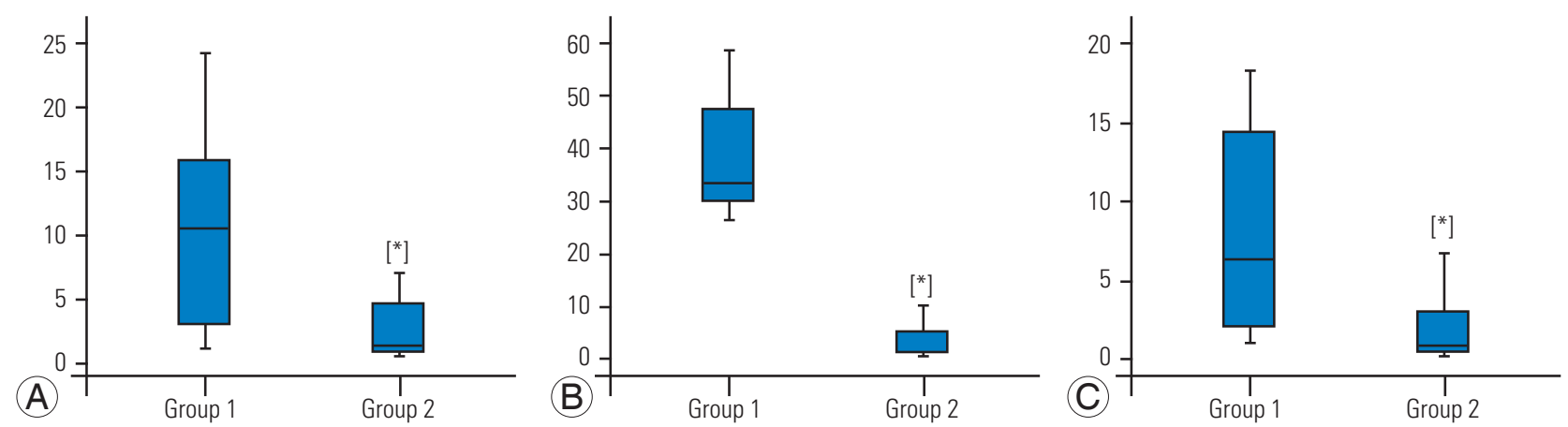

Fig. 2. Comparison of group 1 (short-segment pedicle instrumentation) and 2 (supplemental hook fixation) in test 3 (corpectomy and ventral strut graft) (A), test 4 (corpectomy and posterior strut graft) (B), and test 5 (corpectomy, anterior strut graft, and resected posterior ligamentous complex) (C). Supplemental hook fixation significantly reduces strain ratios on the implant system. ${ }^{*} p=0.000$. 
Table 2. Comparison of ventral and posterior graft positioning according to groups

\begin{tabular}{|c|c|c|c|c|c|c|c|}
\hline \multirow{2}{*}{ Variable } & \multicolumn{3}{|c|}{$\begin{array}{l}\text { Test 3: corpectomy and } \\
\text { ventral strut graft }\end{array}$} & \multicolumn{3}{|c|}{$\begin{array}{c}\text { Test 4: corpectomy and } \\
\text { posterior strut graft }\end{array}$} & \multirow{2}{*}{$p$-value ${ }^{\mathrm{a}}$} \\
\hline & Mean \pm SD & Median & Min-max & Mean $\pm S D$ & Median & Min-max & \\
\hline Group 1: short-segment pedicle instrumentation & $10.3969 \pm 7.6930$ & 10.3706 & $0.76-24.32$ & $37.9129 \pm 10.4884$ & 34.5186 & $26.25-58.77$ & $0.000^{\mathrm{bl}}$ \\
\hline Group 2: supplemental hook fixation & $2.3408 \pm 2.3836$ & 0.9239 & $0.28-6.83$ & $3.1711 \pm 3.4832$ & 1.0694 & $0.59-10.42$ & 0.187 \\
\hline
\end{tabular}

In group 2, ventral positioning of the strut graft shows slightly lower strain ratios, but these were not statistically significant. Data expressed are strain measurements; strain is a unitless quantity: strain= $\mathrm{dL}$ (change in dimension)/L (original dimension).

SD, standard deviation.

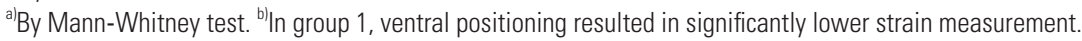

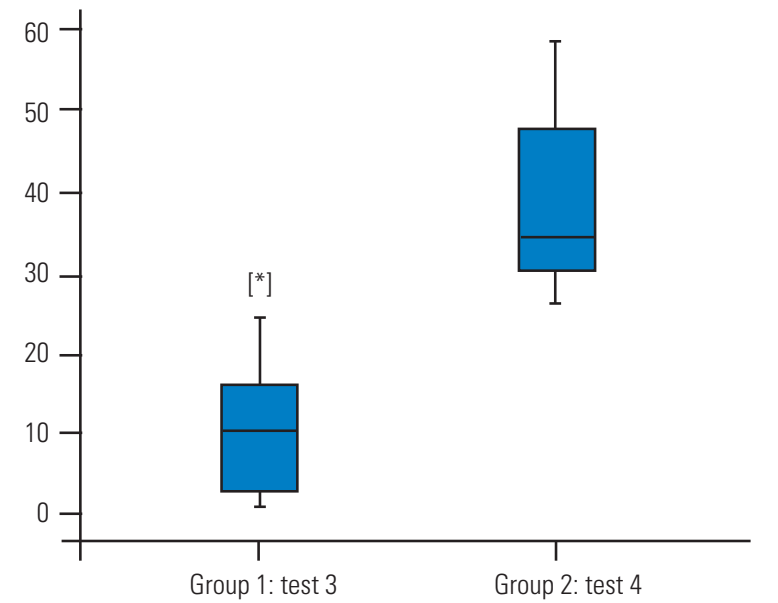

Fig. 3. Comparison of test 3 (corpectomy and ventral strut graft) and test 4 (corpectomy and posterior strut graft) in group 1 (SSPI). Ventral graft positioning significantly reduces strain ratios on the implant system in the SSPI group. SSPI, short-segment pedicle instrumentation. " $p=0.000$.

pectomy), and 6 (corpectomy and resected PLC) did not differ significantly $(p>0.05)$. Lower strain measurements indicate a more stable construct.

\section{The effect of graft positioning}

To determine the effect of graft positioning, we compared the measurements from ventral positioned specimens with the posterior positioned specimens in both groups (Table 2). In the SSPI group, ventral positioning of the strut graft resulted in significantly lower strain measurements $(p=0.000)$. In the SHF group, ventral positioning showed slightly lower strain measurements, but this was not statistically significant ( $p=0.187$ ) (Table 2 , Fig. 3 ).

\section{The effect of posterior ligamentous complex}

To evaluate the effect of PLC resection, we compared the measurements from test 2 with test 6 and those from test
3 with test 5 in both groups (Tables 3, 4). None of the comparisons demonstrated a statistically significant difference $(p>0.05)$.

\section{Discussion}

This study investigated the contribution of long-segment instrumentation with the supplemental hook method to SSPI application, the influence of anterior strut graft to SSPI and supplemental hook instrumentation, the importance of strut graft location, and the role of posterior ligamentous structures in these applications. Significantly increased strain values (decreased stability) were recorded in the corpectomy specimens than in the intact spine. However, in the corpectomy-only specimens (instrumented), when the SSPI and SHF groups were compared, the supplemental hook group showed lower strain values without a statistically significant difference between them $(p>0.05)$ (Table 1). Our results demonstrated that SHF method was significantly more stable than SSPI application when anterior strut grafting is employed, regardless of the location of the strut grafts $(p=0.000)$ (Table 1). In SSPI applications, ventral positioning of the strut graft significantly influences the stability $(p=0.000)$ (Table 2). In supplemental hook applications, there was no significant difference between ventral or posterior positioning of the strut graft due to better stability $(p=0.187)$ (Table 2). Independent of the type of instrumentation, the posterior ligamentous structures did not contribute to stability ( $p>0.005)$ (Tables 3, 4).

Unacceptable failure rates of short segment fixation with progressive kyphotic deformity have been previously reported $[4,6,7,25]$. Other studies have reported that supplemental hook applications significantly contribute to stability and help reduce the failure rates $[1,5,13,14,16]$. De Peretti et al. [11] evaluated the "2-hook screw-1-screw 
Table 3. Comparison of test 2 and test 6 to determine the effect of PLC according to groups

\begin{tabular}{|c|c|c|c|c|c|c|c|}
\hline \multirow{2}{*}{ Variable } & \multicolumn{3}{|c|}{ Test 2: corpectomy } & \multicolumn{3}{|c|}{ Test 6: corpectomy and resected PLC } & \multirow{2}{*}{$p$-value ${ }^{a}$} \\
\hline & Mean \pm SD & Median & Min-max & Mean \pm SD & Median & Min-max & \\
\hline Group 1: short-segment pedicle instrumentation & $28.7952 \pm 26.5260$ & 24.9565 & $2.08-79.47$ & $20.7238 \pm 13.8854$ & 21.0010 & $2.29-44.99$ & 0.575 \\
\hline Group 2: supplemental hook fixation & $15.1328 \pm 14.9398$ & 6.4657 & $2.27-43.36$ & $12.5759 \pm 14.2062$ & 3.4935 & $1.71-40.02$ & 0.113 \\
\hline
\end{tabular}

Resection of PLC did not result in significant difference in either groups. Data expressed are strain measurements; strain is a unitless quantity: strain=dL (change in dimension)/L (original dimension).

PLC, posterior ligamentous complex; SD, standard deviation

${ }^{a}$ By Mann-Whitney test.

hook" instrumentation by regional and mean kyphosis angle measurements and emphasized the benefits of SHF. Argenson et al. $[13,14,16]$ reported similar results in his clinical trials and stressed the efficiency of screw-hook fixation. Chiba et al. [1] reported that SHF decreases the bending moments of pedicle screws by $50 \%$ in flexion and extension. Leduc et al. [5], in on a series of studies based on 25 patients, reported that the $2 \mathrm{HS}-1 \mathrm{SH}$ construct provided significant correction and minimized the risk of failure. In our study, when we compared the data of the SSPI and supplemental hook groups in corpectomy-applied spines, we found lower strain value readings in the supplemental hook group that indicate a more stable fixation; although, these results were not statistically significant ( $p=0.166$ ) (Table 1). The comparisons made after strut graft application demonstrated that supplemental hook application provided a significantly more stable fixation $(p=0.000)$ (Table 1). Ventral positioning of the strut graft in the supplemental hook-applied specimens led to lower strain readings than posterior positioning, but the difference was not statistically significant $(p=0.187)$ (Table 2 ). Thus, our data are consistent with that of previous clinical and biomechanical studies.

According to Benzel [17], the location of the strut graft significantly affects the biomechanical efficacy of the construct. Ventral placement of the graft is biomechanically prudent while positioning the graft dorsally (in the middle column of Denis) provides good axial load-bearing, but a suboptimal ability to prevent kyphosis [17]. Benzel [17] also noted that if the dorsal stability can be achieved, placing the strut graft in a slightly more ventral location may be optimal for better load distribution between the graft and dorsal elements. Polly et al. [26] investigated the biomechanical effects of interbody cages and variations in posterior rod diameter in a simulated single-level spinal fusion. They reported that the presence of interbody cages and their sagittal positioning significantly influences overall construct stiffness and leads to an increased strain on the cage with more anterior positions. They were also inversely related to rod strain. In our study, although there was no statistically significant difference between ventral and posterior positioning of the graft in SHF group ( $p=0.187$ ), ventral positioning of the graft in the SSPI group showed significantly lower strain measurements than the posterior placement of the graft $(p=0.000)$ (Table 2). These results are consistent with those reported by Polly et al. [26].

The role of the posterior ligamentous structures to stability is well-known. Several studies have examined the contribution of each individual ligament. Gillespie and Dickey [20] reported that the supraspinous/interspinous ligament complex was the largest contributor to resist the flexion motion (35.9\%) followed by the intervertebral disc (25.2\%) and the ligamentum flavum (24.7\%). Alapan et al. [23], using a finite element model, found that multiple ligament injuries resulted in a change of the instantaneous center of rotation in all planes as well as load transfer and sharing characteristics of the segment. Li et al. [22], using a cadaveric model, showed that the rupture of the supraspinous ligament or ligamentum flavum resulted in a significant decrease in segmental stability than in the intact and fracture models, particularly in flexion-extension motion. We investigated the role of the posterior ligamentous structures in short segment and supplemental hook instrumentation models. It appears that no study has previously investigated the role of posterior ligaments in posterior instrumentation. Regardless of the instrumentation type, we found no significant differences between the intact and injured groups $(p>0.05)$ (Tables 3,4$)$.

There are some limitations associated with this study. First, due to its availability, we chose to use the calf spine model. Although most biomechanical spine models cannot simulate all biomechanical properties of the human spine, Wilke et al. $[27,28]$ suggested that the calf spine 
Table 4. Comparison of test 3 and test 5 to determine the effect of PLC according to groups

\begin{tabular}{|c|c|c|c|c|c|c|c|}
\hline \multirow[t]{2}{*}{ Variable } & \multicolumn{3}{|c|}{$\begin{array}{l}\text { Test 3: corpectomy and } \\
\text { ventral strut graft }\end{array}$} & \multicolumn{3}{|c|}{$\begin{array}{l}\text { Test 5: corpectomy, ventral strut graft } \\
\text { and resected PLC }\end{array}$} & \multirow{2}{*}{$p$-value ${ }^{\mathrm{a}}$} \\
\hline & Mean \pm SD & Median & Min-max & Mean \pm SD & Median & Min-max & \\
\hline Group 1: short-segment pedicle instrumentation & $10.3969 \pm 7.6930$ & 10.3706 & $0.76-24.32$ & $8.0228 \pm 6.4945$ & 6.2550 & $0.88-18.40$ & 0.448 \\
\hline Group 2: supplemental hook fixation & $2.3408 \pm 2.3836$ & 0.9239 & $0.28-6.83$ & $1.8349 \pm 1.9680$ & 0.7972 & $0.22-6.84$ & 0.355 \\
\hline
\end{tabular}

No significant differences were seen after the resection of PLC in either groups. Data expressed are strain measurements; strain is a unitless quantity: strain=dL (change in dimension)/L (original dimension).

PLC, posterior ligamentous complex; SD, standard deviation.

a)By Mann-Whitney test.

can be considered on a limited basis as a model for the human spine in certain in vitro tests. Second, we used only axial loading tests. The axial loading pattern applies a compressive flexural load on the specimen. As with many other spine surgery clinics, we routinely use a custom-fitted thoraco-lumbo-sacral orthosis (TLSO), which restricts flexion/extension, lateral bending, and rotational movements effectively at least 3 months postoperatively. Considering the use of a TLSO, we only included axial loading patterns in the study. However, flexion/extension, lateral bending, and rotational as well as fatigue tests are critical for determining all physiologic loading conditions. Furthermore, the third limitation of the study is that the in vivo conditions differ from the in vitro environment, due to the absence of soft tissues such as muscles.

\section{Conclusions}

In conclusion, our investigation showed that under axial loading conditions, the most stable method was the SHF in combination with anterior positioned strut graft; however, anterior or posterior positioning did not differ significantly in the supplemental hook group. However, if the short segment fixation is the treatment of choice, ventral positioned strut graft support will be useful in minimizing the risk of implant failure and progressive kyphotic deformity.

\section{Conflict of Interest}

No potential conflict of interest relevant to this article was reported.

\section{Acknowledgments}

The authors thank to Mr. Bahadır UYULGAN (PhD, De- partment of Metallurgical and Materials Engineering, Engineering Faculty, Dokuz Eylul University, Izmir, Turkey) for his technical support in strain measurements.

\section{ORCID}

Sedit Kivanc Muratli: https://orcid.org/0000-0002-7598-2366

Haluk Berk: https://orcid.org/0000-0003-0402-3608

\section{Author Contributions}

Conception and design: SKM, HB; data collection and assembly of data: SKM; administrative support: HB; data analysis and interpretation: SKM; manuscript drafting: SKM, HB; and critical revision of manuscript and supervision: SKM, HB.

\section{References}

1. Chiba M, McLain RF, Yerby SA, Moseley TA, Smith TS, Benson DR. Short-segment pedicle instrumentation: biomechanical analysis of supplemental hook fixation. Spine (Phila Pa 1976) 1996;21:288-94.

2. McNamara MJ, Stephens GC, Spengler DM. Transpedicular short-segment fusions for treatment of lumbar burst fractures. J Spinal Disord 1992;5:183-7.

3. Parker JW, Lane JR, Karaikovic EE, Gaines RW. Successful short-segment instrumentation and fusion for thoracolumbar spine fractures: a consecutive 41/2year series. Spine (Phila Pa 1976) 2000;25:1157-70.

4. McLain RF, Sparling E, Benson DR. Early failure of short-segment pedicle instrumentation for thoracolumbar fractures: a preliminary report. J Bone Joint Surg Am 1993;75:162-7.

5. Leduc S, Mac-Thiong JM, Maurais G, Jodoin A. Posterior pedicle screw fixation with supplemental lami- 
nar hook fixation for the treatment of thoracolumbar burst fractures. Can J Surg 2008;51:35-40.

6. Alanay A, Acaroglu E, Yazici M, Oznur A, Surat A. Short-segment pedicle instrumentation of thoracolumbar burst fractures: does transpedicular intracorporeal grafting prevent early failure? Spine (Phila Pa 1976) 2001;26:213-7.

7. Kramer DL, Rodgers WB, Mansfield FL. Transpedicular instrumentation and short-segment fusion of thoracolumbar fractures: a prospective study using a single instrumentation system. J Orthop Trauma 1995;9:499-506.

8. Sasso RC, Renkens K, Hanson D, Reilly T, McGuire RA Jr, Best NM. Unstable thoracolumbar burst fractures: anterior-only versus short-segment posterior fixation. J Spinal Disord Tech 2006;19:242-8.

9. Alvine GF, Swain JM, Asher MA, Burton DC. Treatment of thoracolumbar burst fractures with variable screw placement or Isola instrumentation and arthrodesis: case series and literature review. J Spinal Disord Tech 2004;17:251-64.

10. Yerby SA, Ehteshami JR, McLain RF. Offset laminar hooks decrease bending moments of pedicle screws during in situ contouring. Spine (Phila Pa 1976) 1997;22:376-81.

11. De Peretti F, Cambas PM, Puch JM, Nasr ZG, Lovet J, Argenson C. Modular construction (2 HS-1 SH), using Cotrel-Dubousset's universal instrumentation for comminuted fractures of the thoracolumbar junction: comparison with various other constructions. Rev Chir Orthop Reparatrice Appar Mot 1994;80:205-16.

12. de Peretti F, Hovorka I, Cambas PM, Nasr JM, Argenson C. Short device fixation and early mobilization for burst fractures of the thoracolumbar junction. Eur Spine J 1996;5:112-20.

13. Argenson C, de Peretti F, Cambas PM. Osteosynthesis of fractures with $\mathrm{CD}$ at the thoracolumbar level. Proceedings of the 8th International Congress on Cotrel-Dubousset Instrumentation; 1991; Minneapolis, USA. Montpellier: Sauramps Medical; 1991. p. 211-4.

14. Argenson C, Lovet J, de Peretti F. The treatment of spinal fractures with Cotrel-Dubousset instrumentation: results of the first 85 cases. Orthop Trans 1989;14:776-7.

15. Tezeren G, Kuru I. Posterior fixation of thoracolumbar burst fracture: short-segment pedicle fixation versus long-segment instrumentation. J Spinal Disord Tech 2005;18:485-8.

16. Argenson C, Lovet J, de Peretti F, et al. Cotrel-Dubousset jnstrumentation for the fixation of thoracic and lumbar vertebral fractures (110 cases). Acta Orthop Traumatol Turc 1993;27:248-56.

17. Benzel EC. Spine instrumentation constructs: region specific considerations. In: Benzel EC, editor. Biomechanics of spine stabilization. 3rd ed. New York (NY): Thieme Medical Publishers; 2015. p. 230-326.

18. Chazal J, Tanguy A, Bourges M, et al. Biomechanical properties of spinal ligaments and a histological study of the supraspinal ligament in traction. J Biomech 1985;18:167-76.

19. White AA, Panjabi MM. The problem of clinical instability in the human spine: a systematic approach. In: White AA, Panjabi MM, editors. Clinical biomechanics of the spine. 2nd ed. Philadelphia (PA): Lippincott Williams \& Wilkins; 1990. p. 278-378.

20. Gillespie KA, Dickey JP. Biomechanical role of lumbar spine ligaments in flexion and extension: determination using a parallel linkage robot and a porcine model. Spine (Phila Pa 1976) 2004;29:1208-16.

21. Heuer F, Schmidt H, Klezl Z, Claes L, Wilke HJ. Stepwise reduction of functional spinal structures increase range of motion and change lordosis angle. J Biomech 2007;40:271-80.

22. Li Y, Shen Z, Huang M, Wang X. Stepwise resection of the posterior ligamentous complex for stability of a thoracolumbar compression fracture: an in vitro biomechanical investigation. Medicine (Baltimore) 2017;96:e7873.

23. Alapan Y, Demir C, Kaner T, Guclu R, Inceoglu S. Instantaneous center of rotation behavior of the lumbar spine with ligament failure. J Neurosurg Spine 2013;18:617-26.

24. Wood KB, Li W, Lebl DR, Ploumis A. Management of thoracolumbar spine fractures. Spine J 2014;14:14564.

25. McCormack T, Karaikovic E, Gaines RW. The load sharing classification of spine fractures. Spine (Phila Pa 1976) 1994;19:1741-4.

26. Polly DW Jr, Klemme WR, Cunningham BW, Burnette JB, Haggerty CJ, Oda I. The biomechanical significance of anterior column support in a simulated single-level spinal fusion. J Spinal Disord 2000;13:5862. 
27. Wilke HJ, Krischak S, Claes L. Biomechanical comparison of calf and human spines. J Orthop Res 1996;14:500-3.
28. Wilke HJ, Krischak ST, Wenger KH, Claes LE. Loaddisplacement properties of the thoracolumbar calf spine: experimental results and comparison to known human data. Eur Spine J 1997;6:129-37. 